\title{
Back to the future: Evidence of ancestral polymorphism in current populations of Anadenanthera colubrina var. cebil by means of Population Graphs
}

\author{
María Eugenia Barrandeguy ${ }^{1,2,3 \otimes}$, and María Victoria García1,2,3
}

\begin{abstract}
Population Graphs includes network theory to infer the relationship among individuals or populations and their respective roles. The hypothesis for this work establishes that Argentinean natural populations of Anadenanthera colubrina var. cebil keep ancestral polymorphism as a consequence of continuous historical distribution of this species in South America. Network analyses were performed centered on individuals and populations using two different measures which integrate genetic information in terms of time and divergence history. These analyses allow us to conclude that the populations of $A$. colubrina var. cebil display geographical isolation even though they are historically related.
\end{abstract}

Keywords: Anadenanthera colubrina var. cebil; ancestral polymorphisms; genetic structure; networks

Received: 15 November 2014

Accepted revised version: 5 January 2015

Published online: 6 April 2015

(C) Barrandeguy and García (2015)

Publisher: Horizon e-Publishing Group

CITATION

Barrandeguy, M. E. and M. V. García. 2015. Back to the future: Evidence of ancestral polymorphism in current populations of Anadenanthera colubrina var. cebil by means of Population Graphs. Plant Science Today 2(2): 65-68. doi: 10.14719/pst.2015.2.2.102

\section{AUTHORS' AFFILIATION}

1 Departamento de Genética. Facultad de Ciencias Exactas, Químicas y Naturales. Universidad Nacional de Misiones; Posadas 3300 Misiones, Argentina

2 Instituto de Biología Subtropical Nodo Posadas (UNaM - CONICET)

3 Consejo Nacional de Investigaciones Científicas y Técnicas (CONICET)

CORRESPONDENCE

\M. E. Barrandeguy E-mail : ebarran@fceqyn.unam.edu.ar

\section{Introduction}

Contemporary genetic variation patterns in populations are a consequence of several historical and contemporary causes. Population Graphs includes network theory, which proposes an exploratory approach to illustrate the relationship among individuals or populations and to infer about their respective roles and importance in the studied systems (Dyer and Nason, 2004).

Seasonally dry tropical forests (SDTFs) show disjunct distribution in South America. This distribution presumably represents fragments of a historical much large and continuous area of this forest type (Prado and Gibbs, 1993). Anadenanthera colubrina var. cebil is a native South American tree species inhabiting SDTFs and it is considered the most paradigmatic species of these forests (Prado and Gibbs, 1993). In a previous study, historical fragmentation was proposed as possible explanation for nuclear and chloroplast genetic structure detected in natural populations of $A$. colubrina var. cebil (Barrandeguy et al., 2014). This result was unexpected for nuclear genome because of high mutation and recombination rates of nuclear microsatellites (nuSSRs), as well as the high levels of gene flow by pollen that can erase the genetic differences (Barrandeguy et al., 2014). However, this previous work did not develop an analysis to test this conclusion for the nuclear genome. In this way, the aim of present study is to determine if polymorphism among individuals and populations exist mainly due to retained ancestral polymorphism or due to current gene flow between individuals. In the first case, we expect the allele length polymorphisms in neutral nuSSRs loci to be distributed evenly across the populations, whereas in the other case we expect the allele length polymorphisms to be shared among spatially close individuals. Taking in account this knowledge, the hypothesis for this work establishes that Argentinean natural populations of $A$. colubrina var. cebil keep ancestral polymorphism as a consequence of continuous historical distribution of this species in South America. 

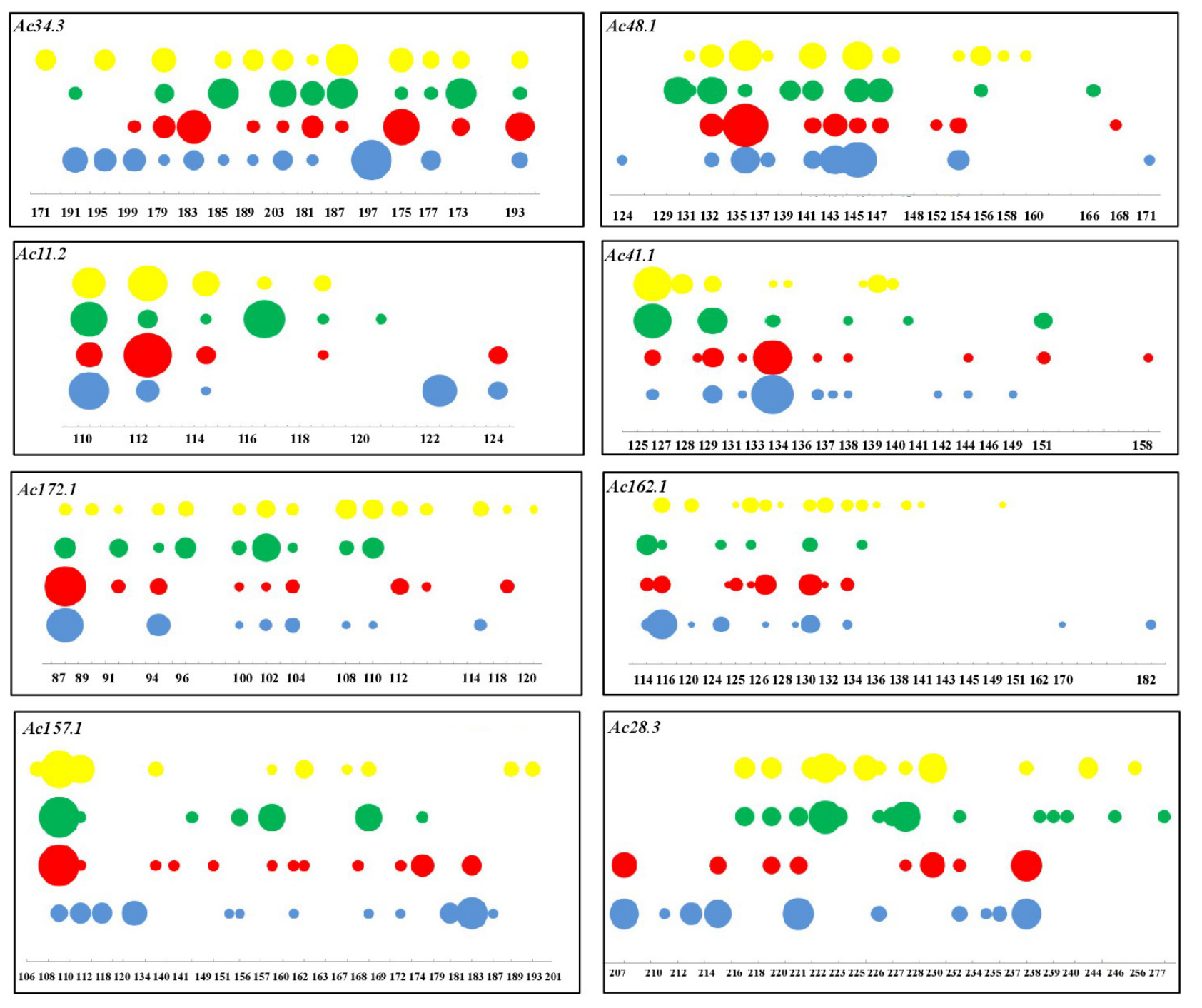

Fig. 1. Allele frequency distribution of microsatellite loci by population. Each circle represents an allele and its frequency is proportional to the size of the corresponding circle (blue: Candelaria, red: Santa Ana, green: Tucumán and yellow: Jujuy).

\section{Materials and methods}

Individuals from two different phytogeographic provinces were analyzed. Sampled populations from the North of Argentina were Candelaria and Santa Ana from Paranaense phytogeographic province and Tucumán and Jujuy from Yungas phytogeographic province. Eight nuclear microsatellite loci were analyzed and the methodology is described in Barrandeguy et al. (2014) (Fig. 1).

Network analyses were performed centered on individuals and populations. The global pattern of genetic relationship among individuals was illustrated by networks built with two different measures. These measures integrate genetic information in terms of time and divergence history: the Rozenfeld Distance index (RD) and the Shared Allele Distance index (SAD). RD index has been developed from Goldstein distance index for use between individuals. RD index provides a parsimonious (i.e. minimal) representation of the genetic distance based on the difference of the nuSSR allele length between individuals (Rozenfeld et al., 2007). On the other hand, SAD index provides the genetic distance between individuals based on the proportion of shared alleles (Chakraborty and Jin, 1993). These genetic distances help to resolve the relationship between individuals at different time-scale: RD index helps to resolve ancestral polymorphism through allele length impinged by slow evolutionary processes, while SAD index helps to understand recent gene flow characterized by direct allelic exchange. 
Table 1. Post-hoc hypotheses for the relationship among populations from network topologies

\section{Distance indices}

\begin{tabular}{|c|c|c|}
\hline SAD - F $F_{S T}$ & RD - GD & potices \\
\hline No groups & No groups & Recent gene flow among historically related populations \\
\hline No groups & Geographical groups & Recent gene flow among historically isolated populations \\
\hline Geographical groups & No groups & $\begin{array}{c}\text { Geographical isolation among historically related } \\
\text { populations }\end{array}$ \\
\hline Geographical groups & Geographical groups & $\begin{array}{c}\text { Geographical isolation among historically isolated } \\
\text { populations }\end{array}$ \\
\hline
\end{tabular}

SAD: Shared Allele Distance index; FST: fixation index; RD: Rozenfeld Distance index; GD: Goldstein Distance index

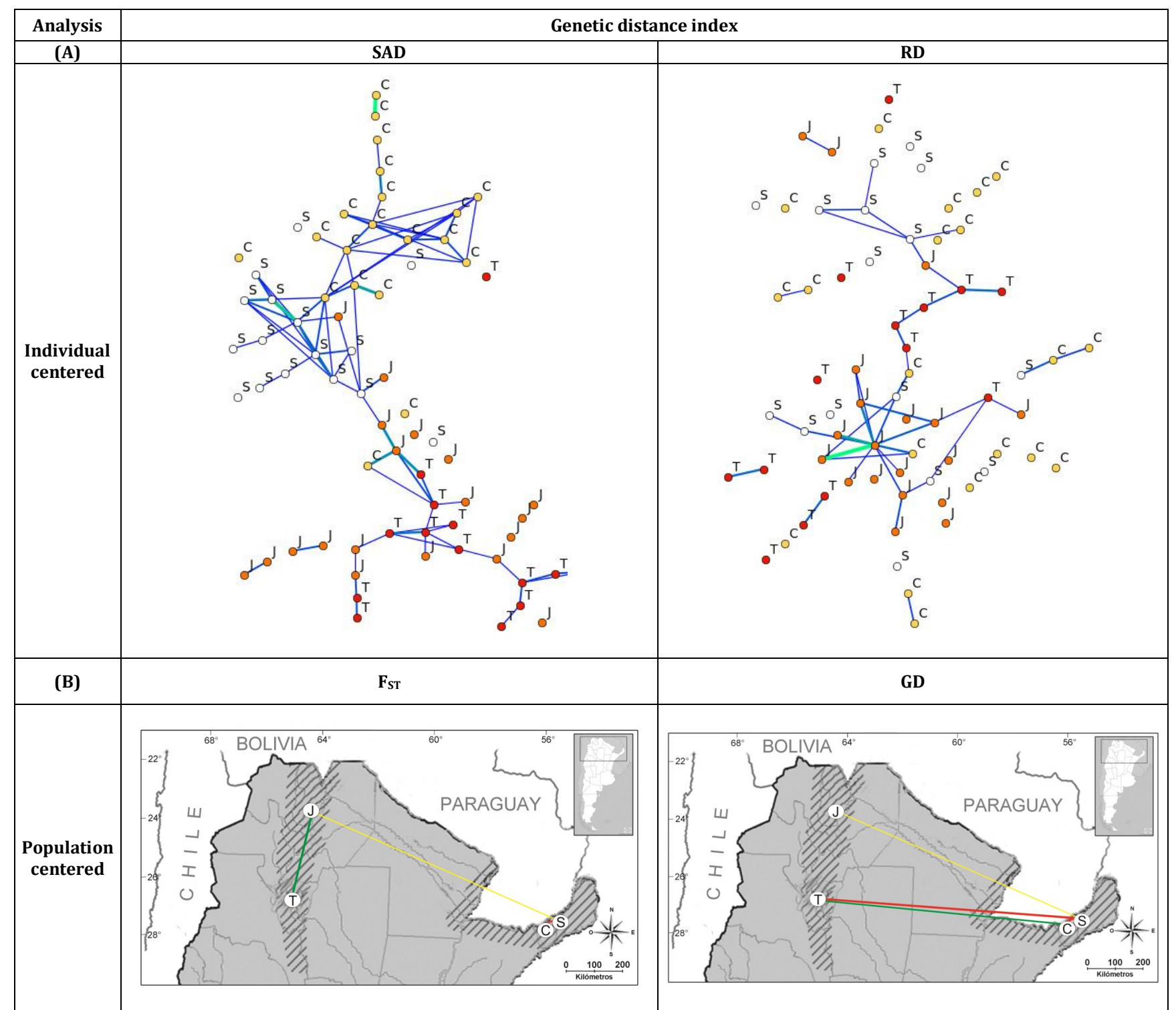

Fig. 2. (A) Networks from individual centered analysis using Shared Allele Distance index (SAD) and Rozenfeld Distance index (RD). (B) Networks from population centered analysis using FST index (FST) and Goldstein Distance index (GD). T: Tucumán, J: Jujuy, C: Candelaria and S: Santa Ana.

In the same way, the global pattern of genetic relationship among populations was illustrated by networks built with two different measures: using
Goldstein distance index (GD) and $\mathrm{F}_{\mathrm{ST}}$ fixation index $\left(\mathrm{F}_{\mathrm{ST}}\right)$. GD index groups populations considering their historical 
origin while $\mathrm{F}_{\mathrm{ST}}$ index takes into account the population structure.

Once the matrices of genetic distance between individuals or populations were estimated, different networks were built considering individuals or populations and genetic distances as nodes or links between them, respectively. Networks were constructed at the percolation threshold (Dp), i.e. the highest distance value until the network collapses. This approach is based on the analysis of the network keeping only essential links illustrating the minimum genetic distance necessary to maintain connectivity across most components of the system. At the percolation threshold network topologies were analyzed. These analyses were performed using EDENetwork software (Kivelä et al., 2014).

\section{Results and discussion}

Several post-hoc hypotheses about genetic and historical evolution of the populations could be made from network topologies (Table 1).

The topology of the network based on SAD index at the percolation thresholds distance $(D p=1.2)$ shows that individuals from the same population are more closely related than individuals from different populations. Nevertheless, that pattern is still maintained when the phytogeographic province is considered (Fig. 2 A). The topology of the network based on the RD index at the percolation thresholds distance ( $D p=9.5)$ reveals lack of genetic groups in coincidence with the geographical origin of individuals in the individuals centered analysis (Fig. 2 A). Absence of geographical groups in RD network could show ancestral polymorphism because of the divergence among alleles is considered. It could be consequence of the continuous distribution of $A$. colubrina var. cebil in the Pleistocene (Prado and Gibbs, 1993). On the other hand, presence of geographical groups in SAD network could show historical fragmentation because of allele frequencies are only considered. It could be consequence of current disjunct distribution of this species which produces population genetic structure because of genetic drift and low gene flow among fragments (Young et al., 1996).

The topology of the network based on $\mathrm{F}_{\mathrm{ST}}$ index at the percolation thresholds $(\mathrm{Dp}=0.1)$ reveals strong relationship between populations from the same phytogeographic province. The strongest relationship was shown between Tucumán and Jujuy (populations from Yungas phytogeographic province) followed by Candelaria and Santa Ana (populations from Paranaense phytogeographic province) whereas the weakest relationship was shown between Jujuy and Santa Ana (populations from different phytogeographic provinces) (Fig. 2 B). The topology of the network based on GD index at the percolation thresholds distance $(D p=33.9)$ reveals different weight relationship between populations from different phytogeographic provinces in the populations centered analysis (Fig. 1 B). Ancestral continuous distribution of this species could explain current relationships among populations from distant geographical origins since these relationships could not be explain as a consequence of recent gene flow. On the other hand, the relationships among populations are according to their geographical distances when genetic structure is considered. This pattern is expected when historical fragmentation is followed by genetic isolation among fragments.

All these analyses allow us to conclude that the populations of $A$. colubrina var. cebil display geographical isolation even though they are historically related. In this way, Population Graphs are an appropriate first approach to assess the origin of the polymorphism in Argentinean natural populations of $A$. colubrina var. cebil regarding to its geographical distribution in the past.

\section{Competing interests}

The authors declare that they have no competing interests.

\section{Acknowledgments}

This study has been supported by PICT $2011 \mathrm{~N}^{\circ} 1795$ from Agencia Nacional de Promoción Científica y Tecnológica (AGENCIA). Authors thank the Consejo Nacional de Investigaciones Científicas y Técnicas (CONICET, Argentina).

\section{References}

Barrandeguy, M.E., García, M.V., Prinz, K., Rivera Pomar, R., and Finkeldey, R. (2014) Genetic structure of disjunct Argentinean populations of the subtropical tree Anadenanthera colubrina var. cebil (Fabaceae). Plant Systematic and Evolution, 300, 1693-1705. doi: 10.1007/s00606-014-0995-y

Chakraborty, R., and Jin, L. (1993) Determination of relatedness between individuals using DNA fingerprinting. Human Biology, 65(6), 875-895.

Dyer, R.J., and Nason, J.D. (2004) Population graphs: the graph theoretic shape of genetic structure. Molecular Ecology, 13(7), 1713-1727. doi: 10.1111/j.1365-294X.2004.02177.x

Kivelä, M., Arnaud-Haond, S., and Saramäki, J. (2014) EDENetworks: A user-friendly software to build and analyse networks in biogeography, ecology and population genetics. Molecular Ecology, doi: 10.1111/1755-0998.12290.

Prado, D.E., and Gibbs, P.E. (1993) Patterns of species distributions in the dry seasonal forests of South America. Annals of the Missouri Botanical Garden, 80, 902-927. doi: 10.2307/2399937

Rozenfeld, A.F., Arnaud-Haond, S., Hernandez-Garcia, E., Eguiluz, V.M., Matias, M.A., Serrao, E., and Duarte, C.M. (2007) Spectrum of genetic diversity and networks of clonal organisms. Journal of the Royal Society Interface, 4(17), 1093-1102. doi: 10.1098/rsif.2007.0230

Young, A., Boyle T. and Brown T. (1996) The population genetic consequences of habitat fragmentation for plants. Trends in Ecology and Evolution 11, 413-418. doi: 10.1016/0169-5347(96)10045-8 